LBL-36565

UC-410

\title{
Surveying the Monument System at Lawrence Berkeley Laboratory's Advanced Light Source Accelerator
}

W. Thur and T. Lauritzen

\author{
Advanced Light Source \\ Accelerator and Fusion Research Division \\ Lawrence Berkeley Laboratory \\ University of California \\ Berkeley, California 94720
}

April 1995

This work was supported by the Director, Office of Energy Research, Office of Basic Energy Sciences,

Materials Sciences Division, of the U.S. Department of Energy under Contract No. DE-AC03-76SF00098. 


\section{DISCLAIMER}

This report was prepared as an account of work sponsored by an agency of the United States Government. Neither the United States Government nor any agency thereof, nor any of their employees, make any warranty, express or implied, or assumes any legal liability or responsibility for the accuracy, completeness, or usefulness of any information, apparatus, product, or process disclosed, or represents that its use would not infringe privately owned rights. Reference herein to any specific commercial product, process, or service by trade name, trademark, manufacturer, or otherwise does not necessarily constitute or imply its endorsement, recommendation, or favoring by the United States Government or any agency thereof. The views and opinions of authors expressed herein do not necessarily state or reflect those of the United States Government or any agency thereof. 


\section{DISCLAIMER}

Portions of this document may be illegible in electronic image products. Images are produced from the best available original document. 


\title{
SURVEYING THE MONUMENT SYSTEM AT LAWRENCE BERKELEY LABORATORY'S ADVANCED LIGHT SOURCE ACCELERATOR*
}

\author{
W. Thur and T. Lauritzen, Advanced Light Source, Lawrence Berkeley Laboratory \\ University of California, Berkeley, CA 94720 USA
}

Particle accelerators with demanding alignment requirements face a need for periodic re-surveying of their reference monument systems. At the ALS, significant foundation settling and the necessary relocation of some floor monuments mean that the entire system of over 100 monuments must be re-surveyed to an accuracy of 100 microns at two year intervals. Last Fall, the monument survey was conducted entirely by the in-house Survey and Alignment crew using a simplified instrument mounting system and an inexpensive commercial software package. Precision levels, plummets, theodolites, and an electronic distance measuring

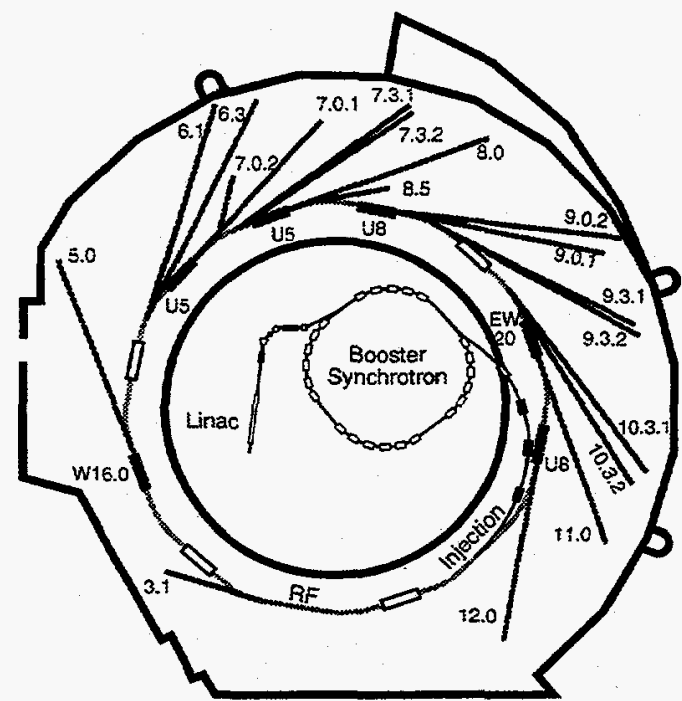

Figure 1: The LBL Advanced Light Source (ALS)

system were used with the innovative "Monopod" instrument mounting system in a cost effective approach to this critical task.

\section{INTRODUCTION}

When the Advanced Light Source synchrotron accelerator was designed in 1987-89, Lawrence Berkeley Laboratory had not built an accelerator facility in many years. There were no survey and alignment specialists on the staff, and certainly no

*This work was supported by the Director, Office of Energy Research, Office of Basic Energy Sciences, Material Sciences Division, U.S. Department of Energy, under Contract No. DE-AC03-76SF00098. one with experience in meeting the \pm 150 micrometre (micron) alignment tolerances specified for the ALS components. Mechanical engineer Ted Lauritzen was given responsibility for survey and alignment. With help from Robert Ruland and Co. of SLAC, the ALS equipped a new survey and alignment team with a well-chosen set of instruments and software to achieve near state-of-the-art alignment tolerances on the 200 meter circumference accelerator. In the process, new and innovative devices and techniques were developed at the ALS to improve the accuracy and the cost effectiveness of survey and alignment. Today, the alignment needs of the accelerator and its growing complement of tangential beamlines are met by a staff of six technicians and a part time engineer.

\section{MONUMENT SURVEYS}

All alignment surveys at the ALS are done with reference to a system of over 100 "monuments" embedded in the concrete slab floor of the building. Ideally, these monuments would be perfectly stable, but floor settling and the addition of new monuments requires that the entire monument network be re-surveyed periodically.

To measure the relative three-dimensional locations of all the monuments, many redundant sightings and measurements are made, with computerized processing of the data. Conceptually, the $100+$ monuments represent a "network" of points linked by lines of sight. Using an optical plummet, a universal instrument mount is securely located at a known height directly above each monument in turn. Theodolites and Mekometers are then mounted for sightings to all the other monuments visible from that location. Wild N3 precision levels sighting to elevation scales provide relative elevation differences between monuments. Kern E2 theodolites provide precise horizontal angles between sighted monuments. Finally, the Kern Mekometer 5000 provides accurate slope distances between itself and a retro reflector at the sighted monument.

Data from the theodolite and the Mekometer sightings is entered into a laptop computer via umbilical cables. Elevation sightings are entered manually by the operator. The output from this data acquisition program is formatted for eventual input into the monument data reduction program, StarNet. StarNet accepts sightings input in any order, and performs a 
least squares "best fit" process on the geometrically redundant data to provide the greatest possible accuracy for the final coordinates of each monument. A "blunder detection" feature identifies any inconsistent input data so that questionable sightings can be repeated. A rigorous error analysis is part of the package. Standard instrument errors, the network geometry, and the level of redundancy are analyzed to specify a two standard deviation "error ellipse" for each monument position.

The complete system described above was used by our six person team in the Autumn of 1994 to re-survey the ALS monument network. The results were gratifying: $100+$ monuments in a circular area of 125 meters diameter were surveyed in three dimensions to an average uncertainty of \pm 89 micrometres. Comparison with the previous monument survey some two years earlier showed that some monument coordinates had changed as much as 1400 micrometres (1.4 $\mathrm{mm}$ ), with an average change of 470 micrometres.

The new monument coordinates will now be used as the frame of reference for all component alignment work done at the ALS. We estimate that future "optimized" monument surveys will be completed in a period of about two months with our six person crew, while the accelerator is running. This capability will allow us to precede each of our major scheduled shut-downs with an updated monument survey, allowing us to maintain the high alignment standards that are needed at the ALS.

In addition to our high quality instruments and survey personnel, three LBL originated innovations contributed to the success of the ALS monument survey:

\section{THREE DIMENSIONAL MONUMENTS}

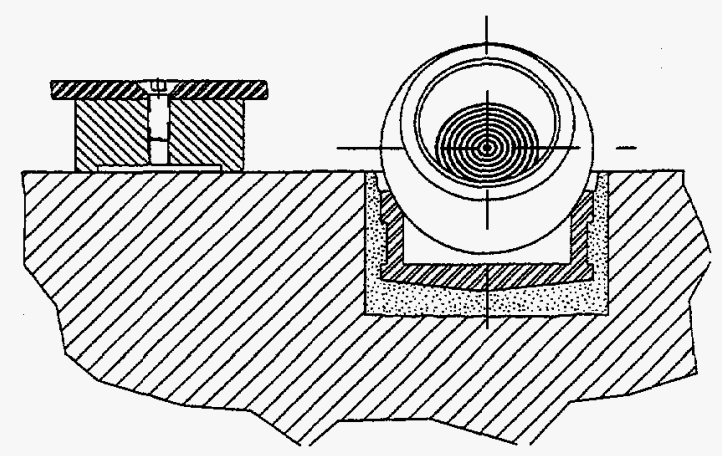

Figure 2: An ALS floor monument

The use of sphere-mounted targets in the conical recessed floor monuments provides a stable and repeatable reference marker capable of being accurately surveyed, and of being accurately referenced in component alignment surveys. Unlike other systems which use separate elevation references, these simple, well-designed monuments tie all three coordinates together for better accuracy and more straightforward use. These monuments are the foundation of our survey system.

The monuments themselves are an LBL design consisting of 17-4PH stainless steel cups epoxy grouted into the concrete floor. A precision ground conical surface supports 3.5 inch diameter Taylor Hobson target mounting spheres which carry sighting targets or corner cube reflectors precisely located at the geometric center of the sphere. The sphere can be swiveled for sighting from any direction, or for elevation measurements made with a direct contact vertical scale. Thus, the monument is three-dimensional; it provides a stable, repeatable reference point in all three dimensions. When not in use, the spheres are removed and protective covers keep out dirt and provide a flush floor surface.

\section{IV. "MONOPOD" INSTRUMENT MOUNTING SYSTEM}

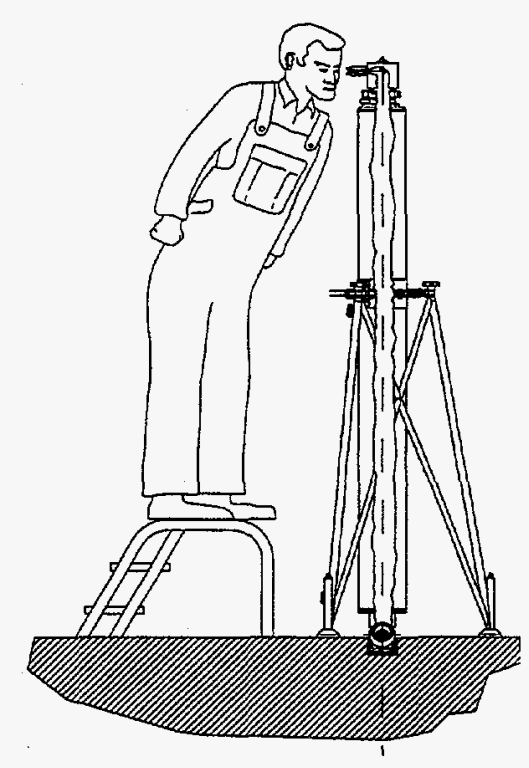

Figure 3: Plumbing a Monopod

Simplistically, the monopod is a 9 inch diameter hollow carbon fiber tube which is used to mount survey sighting instruments at an accurately known elevation directly above a floor monument. At its bottom end, a ground conical socket sits directly on top of a Taylor-Hobson target mounting sphere in a floor monument. At its top end, a modified tribrach instrument mount accepts an optical plummet, a theodolite, a Mekometer, or another target mounting sphere (to allow sighting over obstructions). An auxiliary tripod structure is bolted to the floor around the monopod, and a linkage between the two allows precise plumbing of the monopod over the floor monument. This is accomplished by mounting the optical plummet instrument to the top of the monopod, 
sighting down the bore of the Monopod to the illuminated target mounting sphere in the floor monument. Once the monopod is carefully plumbed, it provides a universal instrument mount at a known height directly above the floor monument. The special carbon fiber construction of the monopod tube provides a near-zero coefficient of thermal expansion, so the known height is extremely stable. Special monopods some 17 feet long are used to reach accelerator floor monuments through radiation shielding roof blocks, so that sightings to the outside monument network can be made. The big advantage of the monopod is that its "built in" elevation dimension eliminates the previous need to take separate elevation sightings for each instrument height.

\section{STARNET DATA REDUCTION SOFTWARE}

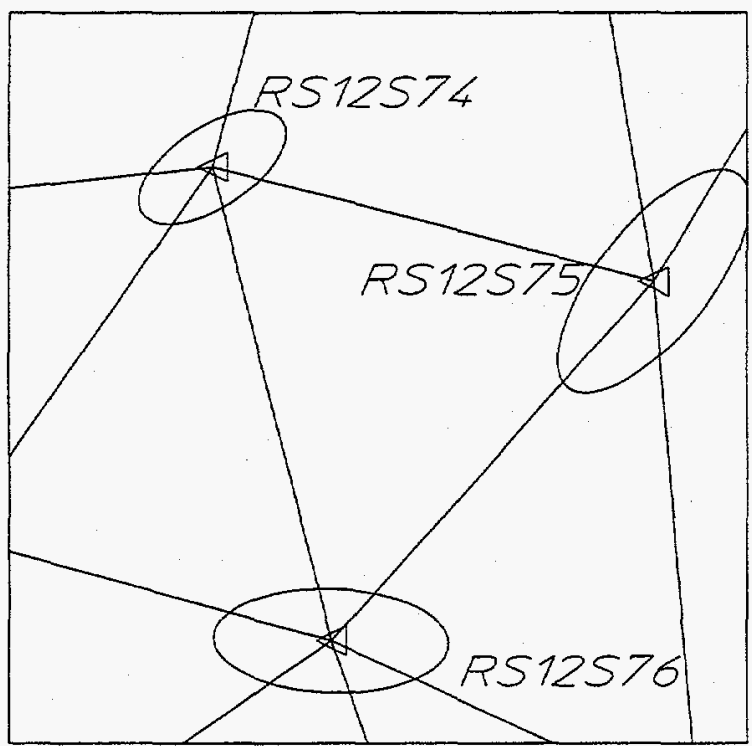

Figure 4: StarNet error ellipses

Although LBL cannot take any credit for the development of the StarNet software package, our discovery and adoption of it have been a tremendous boon to our operation. Previously, the software used for this purpose originated from within the accelerator alignment community. It had evolved over many years into a highly capable, but highly complicated, family of programs best understood by those who wrote them, or at least used them frequently. At our level of occasional use, we were hard pressed to master this esoteric and often unforgiving system. StarNet comes from another world - the world of everyday land surveyors Although land surveyors never approach the level of accuracy we need, their instruments and their techniques are similar to those we use. And, best of all, for wide acceptance their software must be friendly. A well written manual, pull-down menus, and telephone support make StarNet a joy to use. A simple change of units from the scale of kilometers to the scale of meters harnesses all 14 significant digits of StarNet's calculational precision for work at the micrometre level. Its least squares adjustment routines are completely rigorous, and test runs with data sets from earlier surveys produce results identical to those from our previous software. StarNet also includes a simulation mode where survey error ellipses can be predicted based solely upon net geometry and assumed instrument errors, - before a single real sighting is taken[1].

\section{LESSONS LEARNED}

Although we are pleased with our monument survey capability, the recent survey pointed out one way in which our efficiency could be improved: We need more monopods. To make the large number of sightings in our network, too much time was spent setting up, plumbing, and tearing down our set of eight monopods in a leapfrog manner. We would like to build another twelve monopods to minimize this work, and to allow us to complete monument surveys in less time.

\section{ACKNOWLEDGMENTS}

The Monopod instrument mount was originally conceived by Bill Baldock at LBL. The authors also wish to thank Robert Armstrong, Bill Baldock, Richard DeMarco, Alex Gavidia, Donna Jones, and Harry Meyer of the ALS Survey and Alignment crew for their dedicated work in surveying the ALS monument system, and for their helpful suggestions in perfecting the Monopod and the use of StarNet. Thanks also to Rob Duarte for engineering and development of Monopod hardware, and to Dr. Gary Krebs for physics advice and general support.

\section{REFERENCES}

[1] STAR*NET Survey Network Adjustment Program, International Edition, Version 5. Starplus Software, Inc. 460 Boulevard Way, Oakland, CA. 94610, (510) 653-4836. 